\title{
No effect of vitamin D supplementation on markers of immune function in apparently-healthy young adults
}

\author{
M. S. Barnes ${ }^{1}$, L. K. Forsythe ${ }^{1}$, G. Horigan $^{1}$, M. P. Bonham ${ }^{1}$, E. M. Duffy ${ }^{1}$, T. R. Hill ${ }^{2}$, A. J. Lucey ${ }^{2}$, \\ K. D. Cashman ${ }^{2}$, M. Kiely ${ }^{2}$, J. J. Strain ${ }^{1}$ and J. M. W. Wallace ${ }^{1}$ \\ ${ }^{1}$ Northern Ireland Centre for Food \& Health (NICHE), University of Ulster, Coleraine BT52 ISA, UK \\ and ${ }^{2}$ Department of Food and Nutritional Sciences, University College Cork, Cork, Republic of Ireland
}

1,25-Dihydroxyvitamin $\mathrm{D}$, the hormonally-active form of vitamin $\mathrm{D}$ has been shown to be an effective immunomodulator, leading to a cytokine profile that is less inflammatory ${ }^{(1)}$. Vitamin D supplementation has been shown to significantly reduce serum concentrations of TNF $\alpha$ by $10 \%$ and significantly increase serum concentrations of IL-10 by $40 \%$, albeit in patients with congestive heart failure ${ }^{(2)}$. The effect of vitamin D supplementation on immune function in apparently-healthy individuals has not been investigated. Thus, the aim of the present study was to assess the effect of vitamin D supplementation on markers of immune function in a group of young adults.

A total of 236 apparently-healthy young males and females aged 20-40 years were recruited from Coleraine and Cork and randomly assigned to receive 5,10 or $15 \mu \mathrm{g}$ cholecalciferol/d or placebo for 22 weeks ${ }^{(3)} ; 211$ volunteers completed the study with $>85 \%$ compliance (males 107; females 104). Vitamin D status (serum 25-hydroxyvitamin D, S-25(OH)D concentrations) and serum concentrations of the proinflammatory cytokine TNF $\alpha$ and anti-inflammatory cytokine IL-10 were assessed at baseline and post intervention using commerciallyavailable ELISA kits.

One-way between-groups analysis of covariance (ANCOVA) was conducted to assess the effect of treatment on vitamin D status and markers of immune function, controlling for age, gender, BMI and baseline concentrations. Vitamin D supplementation significantly affected S-25(OH)D concentrations (as shown in Table) but did not have an effect on serum concentrations of TNF $\alpha$ or IL-10.

\begin{tabular}{|c|c|c|c|c|c|c|c|c|c|}
\hline & \multicolumn{8}{|c|}{ Treatment group $(\mu \mathrm{g}$ cholecalciferol/d) } & \multirow[b]{3}{*}{$P^{*}$} \\
\hline & \multicolumn{2}{|c|}{$\begin{array}{ll}\text { Placebo }(n 56) \\
\end{array}$} & \multicolumn{2}{|c|}{$5(n 47)$} & \multicolumn{2}{|c|}{$10(n 55)$} & \multicolumn{2}{|c|}{$15(n 53)$} & \\
\hline & Median & IQR & Median & IQR & Median & IQR & Median & IQR & \\
\hline \multicolumn{10}{|c|}{$\mathrm{S}-25(\mathrm{OH}) \mathrm{D}(\mathrm{nmol} / \mathrm{l})$} \\
\hline Pre & 66.1 & $57.2-95.5$ & 60.1 & $50.0-91.5$ & 72.2 & $53.2-95.4$ & 75.9 & $55.4-89.4$ & \\
\hline Post & $36.9^{\mathrm{a}}$ & $30.9-48.1$ & $50.4^{\mathrm{b}}$ & $45.0-60.4$ & $59.6^{\mathrm{c}}$ & $51.3-70.3$ & $69.0^{\mathrm{d}}$ & $59.1-84.4$ & $<0.0001$ \\
\hline \multicolumn{10}{|c|}{ Serum TNF $\alpha(\mathrm{pg} / \mathrm{ml})$} \\
\hline Pre & 1.62 & $1.29-2.14$ & 1.53 & $1.16-1.86$ & 1.38 & $1.20-1.88$ & 1.48 & $1.29-1.90$ & \\
\hline Post & 1.51 & $1.15-1.98$ & 1.35 & $1.05-1.66$ & 1.45 & $1.11-1.92$ & 1.440 & $1.10-1.97$ & 0.942 \\
\hline \multicolumn{10}{|c|}{ Serum IL-10 (pg/ml) } \\
\hline Pre & 0.87 & $0.76-1.07$ & 0.80 & $0.71-0.96$ & 0.87 & $0.79-1.06$ & 0.85 & $0.71-1.03$ & \\
\hline Post & 0.89 & $0.78-1.0$ & 0.88 & $0.72-1.07$ & 0.96 & $0.80-1.14$ & 0.91 & $0.74-1.01$ & 0.346 \\
\hline
\end{tabular}

IQR, interquartile range. ${ }^{\text {a,b,c,d }}$ Means with unlike superscript letters were significantly different between groups (ANOVA; $\left.P<0.05\right)$. *Effect of treatment assessed by ANCOVA controlling for age, gender, BMI and baseline concentrations.

In conclusion, vitamin D supplementation had a significant effect on vitamin D status in a dose-responsive manner, but did not affect serum concentrations of TNF $\alpha$ or IL-10 in young adults. It has however, been suggested that circulating S-25(OH)D concentrations $>100 \mathrm{nmol} / \mathrm{l}$ are required to optimise all vitamin D-dependent functions, levels higher than those observed in the present study, even after supplementation.

This work was supported by the UK Food Standards Agency.

1. Holick MF (2005) South Med J 98, 1024-1027.

2. Schleithoff SS, Zittermann A, Berthold HK et al. (2006) Am J Clin Nutr 83, 754-759.

3. Cashman KD, Hill TR, Lucey AJ et al. (2008) Am J Clin Nutr 88, 1535-1542. 